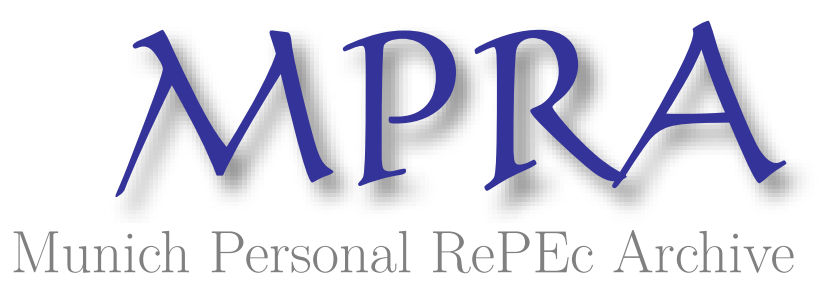

\title{
Transboundary Renewable Resource Management: A Dynamic Game with Differing Non-Cooperative Payoffs
}

Ida, Ferrara and Paul, Missios

York University, Ryerson University

19 August 1996

Online at https://mpra.ub.uni-muenchen.de/70749/

MPRA Paper No. 70749, posted 16 Apr 2016 16:43 UTC 
TRANSBOUNDARY RENEWABLE RESOURCE

MANAGEMENT: A DYNAMIC GAME WITH

DIFFERING NON-COOPERATIVE PAYOFFS

\author{
Ida Ferrara, \\ Department of Economics, \\ York University \\ and \\ Paul C. Missios, \\ Department of Economics, \\ York University
}

Revised August 19 ${ }^{\text {th }}, 1996$ 


\begin{abstract}
Recent conflicts over fish stocks, such as salmon and turbot, have revived public interest in the optimal management of transboundary renewable natural resources. Given that enforcement of binding contracts is often a major obstacle, dynamically consistent or selfenforcing contracting, as proposed by Vislie (1987), must be relied upon. A more general model is developed which recognizes that, in the absence of a cooperative agreement, two countries may enjoy differing economic payoffs. The predictions of the model are consistent with and provide insights into the particulars of the recent disputes.
\end{abstract}




\section{Transboundary Renewable Resource Management:A Dynamic Game With Dif- fering Non-Cooperative Payoffs*}

\section{Introduction}

Recent conflicts between Canada and the United States over Pacific salmon and between Canada and the European Union (EU) over turbot have revived public interest in the optimal management of jointly exploited renewable resources. Whether cooperation or non-cooperation between the countries involved in any such conflict is more desirable has been previously analyzed in theory, with the finding that the cooperative solution Pareto-dominates the non-cooperative outcome, given that under cooperation the externality, or common property resource aspect, is fully taken into account in the choice of the optimal total harvest. This result is not necessarily inconsistent with the recurring of fish wars (non-cooperation) in a world of utility-maximizing agents, as non-cooperative outcomes are often short-lived and result in negotiated settlements preferable over competition to all parties. In the literature on cooperative free-access fishery models, the article by Gordon Munro (1979) and that by Jon Vislie (1987) are the most relevant to the present paper, even though our emphasis will be on the second one. Gordon Munro, in his pivotal 1979 article, considers two countries exploiting a transboundary fish stock under the assumption of a binding cooperative agreement and Nash bargaining. ${ }^{1}$ Jon Vislie, in his 1987 comment on Munro's article, relaxes the restrictive requirement that the two countries are legally bound to their commitments concerning future actions, and uses a simplified (two-period) version of Munro's model to examine the scenario where the contract between the countries must

\footnotetext{
${ }^{1}$ Plourde and Yeung (1989) examine binding cooperative agreements like Munro (1979) but with $n \geq 2$ players.
} 
be self-enforcing. Notwithstanding its contributions, Vislie's analysis depends on the unrealistic assumption that the breakdown (no-agreement) payoffs to the countries are the same, implying an equal division of the final-period harvest. Indeed, the country adjacent to the fish stock may have better information regarding the best fishing spots or some other advantage which would lead to a non-cooperative payoff higher than that of the other country. ${ }^{2}$ Furthermore, Vislie's results would apply to the above mentioned Canadian conflicts, in particular the one over turbot, only if Canada has a lower discount rate than the European Union, that is, only if Canada is more future-oriented. By allowing for differing breakdown payoffs, we are able to show that the second-period share for the country with the higher payoff, denoted the Home country, ${ }^{3}$ is greater than fifty percent. This is intuitively appealing, as the country that gains more from non-cooperation must be compensated with a higher share under cooperation. We then derive the effects of differing second-period shares on the first-period shares, as well as on the first- and second-period harvests, and, finally, compare the predictions of the model with the reality of the current turbot and salmon disputes. The model can be applicable to both situations in which the stock migrates across the boundary between the waters of two nations, and those in which the stock migrates between the waters of one nation and the high seas ("straddling stocks"), the latter only when there are two countries and barriers to entry.

\footnotetext{
${ }^{2}$ Another explanation of differing non-cooperative payoffs is that the harvesting cost functions of the two countries may be different. We thank an anonymous referee for mentioning this possibility. For simplicity, however, we assume that differences in breakdown payoffs arise for reasons other than costs, and therefore assume identical cost functions.

${ }^{3}$ The Home country is assumed to have a higher payoff in each period due to its geographic proximity to the fish resource and, as a result, to the advantage of more diverse technologies. The Foreign country can only employ "offshore" technologies that must incorporate both the harvesting and the processing (e.g. canning or freezing) of the fish caught. "Home" and "Foreign" are used throughout the paper for ease of exposition, to more clearly differentiate between the country with the higher non-cooperative payoff from the country with the lower non-cooperative payoff. The model presented remains applicable to the management of stocks between countries equally distant from the stock, as long as one country has a higher breakdown payoff than the other, as can be witnessed in the Canada-U.S. dispute over particular salmon species.
} 
The material covered in this paper is organized in four sections. In section 2 we show that the Home country receives a second-period share of the total harvest greater than that of the other country, denoted the Foreign country. In section 3 we present a two-period model of the type used by Vislie but with the additional requirement that the results derived in section 2 hold, namely, that the second-period shares are more than fifty percent for the Home country and, accordingly, less than fifty percent for the Foreign country. In section 4 we relate the predictions of the model to the current disputes and draw implications for present and future actions on the part of both countries involved in these conflicts. In section 5 we offer concluding remarks and comment on the contribution of the paper to the management of joint-access renewable resources.

\section{The Second-Period Sharing Rule}

Following Munro and Vislie, we consider two countries facing a world demand for harvested fish that is infinitely elastic, implying a constant price, $p$, and an identical unit cost of harvesting in any period $t$ that is dependent only upon the fish stock, $x$, at the beginning of the same period, $C\left(x_{t-1}\right)$. In a bargaining situation where agreements are not juridically binding, the two countries maximize in each period the Nash-product, ${ }^{4}$ that is, the product of their individual gains from cooperation, such that their harvest shares (both non-negative) sum to unity, and

\footnotetext{
${ }^{4}$ See Nash (1953) for the proofs of the desirable properties of the Nash-product (feasibility, independence of irrelevant alternatives, Pareto-optimality, rationality, and symmetry). Recently, there has been some debate over the validity of the Nash Bargaining Solution and the Nash-product as self-enforcing. For alternative views in the fisheries literature, see Kaitala and Pohjola (1988) or Armstrong (1994).
} 
subject to the resource constraint

$$
x_{t}=x_{t-1}+F\left(x_{t-1}\right)-h_{t} \geq x^{*},
$$

where $F\left(x_{t-1}\right)$ is the natural growth function, $h_{t}$ is the total harvest in period $t$, and $x^{*}$ is some critical stock level. Under the assumption that the second-period non-cooperative payoff of the Home country, $v$, is larger than that of the Foreign country, $w$, the Nash-product for that period is given by

$$
\left[a_{2}\left(p-C\left(x_{1}\right)\right) h_{2}-v\right]\left[\left(1-a_{2}\right)\left(p-C\left(x_{1}\right)\right) h_{2}-w\right],
$$

where $a_{2}$ is the second-period harvest share of the Home country. Maximization of $(2.2)$ with respect to $a_{2}$, under the assumption that the fish stock at the end of the second period is equal to the critical level, yields

$$
a_{2}=\frac{1}{2}+\frac{(v-w)}{2 h_{2}\left[p-C\left(x_{1}\right)\right]},
$$

which is obviously greater than one-half. In the following section we take this result into account when determining the first-period sharing rule and the fish stock to be left unharvested in the first period.

\section{A Dynamically Consistent Two-Period Agreement}

The countries negotiate the agreement at the beginning of the first period by maximizing the two-period Nash-product,

$$
\left(V^{a}-V^{0}\right)\left(W^{a}-W^{0}\right),
$$


where

$$
\begin{gathered}
V^{a}=a_{1}\left[p-C\left(x_{0}\right)\right]\left(x_{0}+F\left(x_{0}\right)-x_{1}\right)+a_{2} b_{H}\left[p-C\left(x_{1}\right)\right]\left(x_{1}+F\left(x_{1}\right)-x^{*}\right), \\
W^{a}=\left(1-a_{1}\right)\left[p-C\left(x_{0}\right)\right]\left(x_{0}+F\left(x_{0}\right)-x_{1}\right)+\left(1-a_{2}\right) b_{F}\left[p-C\left(x_{1}\right)\right]\left(x_{1}+F\left(x_{1}\right)-x^{*}\right),
\end{gathered}
$$

and $V^{0}$ and $W^{0}$ are the present values of payoffs under no agreement, ${ }^{5}$ and where $b_{H}$ is the discount factor for the Home country and $b_{F}$ is the discount factor for the Foreign country. However, unless $a_{2}$ in (3.2) and (3.3) is determined according to (2.3), the contract will not be self-enforcing and the countries will have an incentive to deviate from the negotiated shares.

Under the constraints that $a_{1}$ ranges between zero and one, and that the fish stock at the beginning of the second period is not less than the critical level, the solution to the above maximization problem must satisfy

$$
\left\{\left[p-C\left(x_{0}\right)\right] h_{1}\right\}\left(W^{a}-W^{0}\right)-\left\{\left[p-C\left(x_{0}\right)\right] h_{1}\right\}\left(V^{a}-V^{0}\right)=0
$$

and

$$
\begin{aligned}
& \left.a_{1}\left[p-C\left(x_{0}\right)\right]+\frac{b_{H}}{2}\left\{C^{\prime}\left(x_{1}\right) h_{2}-\left[p-C\left(x_{1}\right)\right]\left[1+F^{\prime}\left(x_{1}\right)\right]\right\}\right\}\left(W^{a}-W^{0}\right) \\
= & \left\{-\left(1-a_{1}\right)\left[p-C\left(x_{0}\right)\right]+\frac{b_{F}}{2}\left\{-C^{\prime}\left(x_{1}\right) h_{2}+\left[p-C\left(x_{1}\right)\right]\left[1+F^{\prime}\left(x_{1}\right)\right]\right\}\right\}\left(V^{a}-V^{0}\right)
\end{aligned}
$$

\footnotetext{
${ }^{5}$ As discussed in the Introduction, $V^{0}$ is assumed to be greater than $W^{0}$.
} 
From (3.4), using (3.5) and substituting for $a_{2}$, we obtain

$$
a_{1}=\frac{1}{2}+\frac{\left[\left(1-a_{2}\right) b_{F}-a_{2} b_{H}\right]\left[p-C\left(x_{1}\right)\right] h_{2}+\left(V^{0}-W^{0}\right)}{\left(b_{H}+b_{F}\right)\left\{-C^{\prime}\left(x_{1}\right) h_{2}+\left[p-C\left(x_{1}\right)\right]\left[1+F^{\prime}\left(x_{1}\right)\right]\right\} h_{1}}
$$

which gives the first-period harvest share for the Home country as a function of, among other variables, the second-period shares. Further, we find that the optimal level of $x_{1},{ }^{6}$ which is implicit in (3.5), depends only upon the two discount factors, the price, and the initial and critical stock levels, and is therefore independent of the harvest shares. ${ }^{7}$ The immediate result of this independence is that the assumption of differing non-cooperative payoffs has no impact on the choice of the optimal first- and second-period harvests, however, it does have an effect on that of the first- and second-period shares.

From (3.6), we know that $a_{1}$ is greater than fifty percent in situations where the two countries have identical discount rates, i.e., $b_{H}=b_{F}=b \geq 0$. In fact, substituting for $a_{2}$ in the numerator of the second term on the right-hand-side of (3.6), denoted $A$, we have

$$
A=\left(V^{0}-W^{0}\right)-b(v-w)
$$

which is greater than zero, given that it is simply the difference between the first-period noagreement payoff of the Home country and that of the Foreign country, and, by assumption, that difference is positive in any period. ${ }^{8}$ For differing discount factors, specifically $b_{H}>b_{F}$,

\footnotetext{
${ }^{6}$ The choice variables are in actuality $a_{1}$ and $h_{1}$. However, $h_{1}$ is a function of the initial fish stock, which is given, and $x_{1}$, so that the countries choose the optimal $h_{1}$ by maximizing with respect to $x_{1}$.

7 (3.5) also includes the "marginal stock effect" described by Clark (1976), in which the countries both have an incentive to reduce their current harvest as this will result in a higher stock level and thus lower harvesting costs in the following period due to the assumption of $C^{\prime}(x)>0$.

${ }^{8}$ The denominator of the second term on the right-hand-side of $(3.6)$ is equal to $2\left[p-C\left(x_{0}\right)\right] h_{1}$, from $(3.5)$, and is clearly positive.
} 
implying that the Home country is more future- or conservation-oriented, we know that $a_{1}$ is lower than in the previous case where $b_{H}=b_{F},{ }^{9}$ but we cannot say whether $a_{1}$ is less or greater than fifty percent, since

$$
A=\left(V^{0}-W^{0}\right)+\frac{1}{2}\left(b_{F}-b_{H}\right)\left[p-C\left(x_{1}\right)\right] h_{2}-\frac{1}{2}\left(b_{H}+b_{F}\right)(v-w),
$$

the sign of which is ambiguous because of an additional negative term (the second term on the right-hand-side) and depends on the magnitude of the Home country's non-cooperative advantage over the Foreign country $(v-w)$. In particular, the larger the present value of the Home country's non-cooperative payoff relative to that of the Foreign country, the more likely the Home country will have a larger cooperative harvest share (more than fifty percent) not only in the second period but also in the first period under a cooperative agreement.

To better illustrate the above results, we can assume that the two countries' default payoffs are constant over time, implying that $V^{0}=v+b_{H} v$ and $W^{0}=w+b_{F} w$, and, using the equilibrium value of $a_{2}$ from (2.3), we can rewrite (3.8) as

$$
A=(v-w)+\frac{\left(b_{F}-b_{H}\right)\left[\left(1-a_{2}\right) v-a_{2} w\right]}{\left(2 a_{2}-1\right)} .
$$

We then have that, if $b_{F}=b_{H}, a_{1}$ is greater than one-half as $A=v-w>0$, and, if $b_{F}>$ $b_{H}$, whether $a_{1}$ is greater than one-half depends upon the difference between $v$ and $w$, which, according to (2.3), also determines by how much $a_{2}$ exceeds fifty percent.

\footnotetext{
${ }^{9}$ The derivative of $a_{1}$ with respect to $b_{H}$ is negative, and that with respect to $b_{F}$ is positive.
} 


\section{Applications to Current Disputes: The Pacific Salmon and Turbot}

\section{Cases}

Both Munro and Vislie recognize that conflicts in the management of transboundary renewable resources may arise from differences in perceptions of the social rate of discount or rate of time preference. ${ }^{10}$ However, in reality, disputes do occur even between countries such as Canada and the United States, which can be considered to have identical discount rates because of similar social, cultural, political, and economic infrastructures. Of interest in the current context, is the Canada-US salmon dispute, which goes back more than a century, with the first formal agreement, the Bryce-Root Treaty of 1908, governing only the Fraser river sockeye run of British Columbia. Later arrangements extended management coverage to other major salmon species, the Fraser pinks, and the Washington- and Oregon-spawned cohos and chinooks. In spite of these treaties, mismanagement and overfishing occurred to the point of near extinction for many commercially important spawning runs in both Canada and the United States. In fact, in response to Bill Clinton's decision to ban salmon fishing in the area from California to the Canadian border where the stocks were badly depleted, and to the resulting US fishermen's resolution to travel to Alaska, adding to the pressure on the salmon originating in $\mathrm{BC}$, the Canadian Department of Fisheries and Oceans instructed Canadian fishermen to aggressively fish the Fraser river in order to deny the catch to Americans, thus contributing to devastate the west coast salmon fishery.

The Canada-US dispute provides an example of the dangers of competition in commonaccess fisheries in the presence of poor enforcement of cooperative agreements and uncertainty

\footnotetext{
${ }^{10}$ Munro also examines differences in fishing effort costs and consumer preferences as a potential source of conflicts in resource management.
} 
about stock levels. Unfortunately, little can be done to alleviate the impact of the stock level uncertainty on the long-term fishery management. However, we can circumvent the problems of monitoring and enforcement, sometimes excessively costly or impossible, and ensure the future viability of fish stocks, or, for that matter, any other renewable natural resource, by relying on a self-enforcing contract of the type modeled in sections 2 and 3 above.

In order to evaluate the positions of Canada and the United States in potential treaties, we need to establish whether the two countries have identical non-cooperative payoffs and, if not, which country has an advantage. ${ }^{11}$ For example, since Canada and the United States are likely to have the same discount factor, we are able to conclude that the country with the higher no-agreement payoff will have to receive more than fifty percent of the allowable catch in the present as well as in the future. On the other hand, if neither of them has an advantage, they will always share the harvest equally. In the salmon case, we know that Americans catch some of the Canada-spawned fish (mainly pinks and sockeye) as they pass through American waters, and, similarly, Canadians catch some of the US-spawned fish (mainly cohos and chinooks) as they pass through Canadian waters. Of the four named salmon species, sockeye and chinooks are economically the most valuable. Now, as sockeye is the most important salmon to the British Columbia fishing industry, Canada will probably have more to lose than the United States under non-cooperation, and this can be considered to imply a higher no-agreement payoff to the United States, in which case our model predicts a larger harvest share of sockeye to the United States than to Canada under cooperation in the present and the future. Similarly, given that chinooks

\footnotetext{
${ }^{11}$ Munro and Stokes (1989) point out that the salmon dispute is not simply between Canada and the United States, as there is considerable antagonism between Washington, Oregon and Alaska. However, if we assume that the United States can solve their internal conflicts by a self-enforcing division of their national quota, then Canada will have to negotiate only with the United States as a whole.
} 
are the most important salmon species marketed by Americans, we expect Canada to always have a larger cooperative harvest share of chinooks.

The other current conflict which we can analyze in the context of the above model is that between Canada and the European Union over turbot, ${ }^{12}$ a member of the flounder family, which is primarily used for fish sticks in North America and smoked in Europe. The dispute concerns the area of the Grand Banks of Newfoundland outside the two hundred nautical mile limit of Canada, ${ }^{13}$ where European (Spanish and Portuguese) vessels have been fishing above the quota set for the European Union, historically below fifty percent, by the fifteen-country North Atlantic Fishery Organization (NAFO). ${ }^{14}$ To justify overfishing, the European Union has cited the low Canadian share of the turbot caught over recent years, around twenty percent, as an indication of excessively high, over sixty percent, NAFO shares for Canada. In contrast, Canada has claimed that its low catch share has been the immediate consequence of the continued overfishing by the European Union and other NAFO members.

If Canada and the European Union have the same attitude towards the future, that is, if they have the same discount factor, and if Canada, being the Home country, has a better position under non-cooperation, we find that our model supports NAFO's decision to assign Canada a harvest share continually greater than fifty percent. However, many, and the Canadian Fisheries Minister Brian Tobin himself, have argued that Canada is significantly more conservationist than the European Union. In support of this argument, European interest rates, which can be regarded as a proxy for discount rates, have been traditionally higher than Canadian interest

\footnotetext{
${ }^{12}$ It must be noted that the model of sections 2 and 3 is applicable to "straddling stock" management when there are only two countries involved, as otherwise competition on the high seas will disrupt the duopolistic equilibrium. While countries other than Canada and the European Union do fish for turbot, none are significant as these two countries.

${ }^{13}$ The area is commonly known as the "nose" and "tail" of the Grand Banks.

${ }^{14}$ In 1995 , the quota set for the EU by NAFO was 3,400 tonnes, or $12.6 \%$ of the total allowable catch.
} 
rates, implying a lower discount factor for the European Union, and thus a greater futureorientation for Canada. Under these conditions, our model predicts a larger cooperative harvest share in the present for the European Union if the effect of differing discount factors outweighs that of differing no-agreement payoffs. Formally, the European Union is to receive a higher share in the present if

$$
\frac{1}{2}\left(b_{H}-b_{F}\right)\left[p-C\left(x_{1}\right)\right] h_{2}>\left(V^{0}-W^{0}\right)-\frac{1}{2}\left(b_{H}+b_{F}\right)(v-w)
$$

that is, if the average discounted second-period net benefit from the Home country's higher discount factor is greater than the average "perceived value" of the first-period no-agreement payoff differential, ${ }^{15}$ or, under the assumption of constant default payoffs for both countries and by $(2.3)$, if

$$
b_{H}-b_{F}>\frac{\left[a_{2}(v-w)-\left(1-a_{2}\right)(v-w)\right]}{\left[\left(1-a_{2}\right) v-a_{2} w\right]} .
$$

This seems to be the case; in fact, in September 1995, Canada and the European Union succeeded in reaching an agreement with NAFO, whereby the European Union is entitled to fifty-five percent of the 1996 total allowable catch.

\section{Concluding Remarks}

In this paper we have suggested that countries involved in conflicts over transboundary fish stocks may not enjoy equal default (breakdown) positions, and, consequently, may not share

\footnotetext{
${ }^{15}$ The right-hand-side of (4.1) is the difference between the present value of the two-period no-agreement payoff differential $\left(V_{0}-W_{0}\right)$ and the second-period non-cooperative payoff differential discounted by the average discount factor.
} 
the joint-harvest equally, even if they have identical fishing costs and social discount factors. Differing no-agreement payoffs may arise from the Home country's geographic proximity to the fish stock which confers the advantage of more diverse technologies. In fact, the Home country has the option to separate the harvesting of the fish from the processing operation, a luxury the Foreign country does not possess.

Our model, however, is not limited to situations where countries are equally future-oriented. For example, in the turbot conflict between Canada, possibly more conservationist, and the European Union, our analysis is able to explain recent developments, according to which the European Union is to receive a harvest share greater than fifty percent in 1996. Whether or not a less conservationist Foreign country gets more than half of the total allowable catch depends on the magnitude of the effect of the discount factor differential $\left(b_{H}-b_{F}\right)$ relative to that of the non-cooperative payoff differential $\left(V^{0}-W^{0}\right)$. Specifically, a more substantial discount factor differential, implying a more sizable disparity in the two countries' preferences for conservation, signifies a larger current harvest share for the less conservationist country; on the other hand, a more advantageous position of the more future-oriented country, implying a greater breakdown payoff differential, leads to a smaller current harvest share for the less conservationist country. In the light of the September 1995 settlement between Canada and the European Union, our model suggests that Canada is, as claimed, much more conservationist or future-oriented than the European Union, and thus agreed to a share less than fifty percent for 1996, despite its better default position.

Notwithstanding its simplicity, our model does provide notable insights into the real world international management affairs where cooperation is the norm and conflicts are a transitory and often short-lived phenomenon. In fact, the analysis performed above is not only applicable 
to fishery management but also to any other renewable natural resource which happens to be jointly exploited by two countries.

* Comments by Charles Plourde and two anonymous referees are greatly appreciated. 


\section{References}

Armstrong, C. W. (1994), "Cooperative Solutions in a Transboundary Fishery: The RussianNorwegian Co-Management of the Arcto-Norwegian Cod Stock," Marine Resource Economics 9: $329-51$.

Clark, Colin W. (1976), Mathematical Bioeconomics: The Optimal Management of Renewable Resources, (John Wiley \& Sons, Inc.), New York.

Kaitala, Veijo, and Matti Pohjola (1988), "Optimal Recovery of a Shared Resource Stock: A Differential Game Model with Efficient Memory Equilibria," Natural Resource Modeling 3: 91-119.

Munro, Gordon R. (1979), "The Optimal Management of Transboundary Renewable Resources," Canadian Journal of Economics 12: 355-376.

Munro, Gordon R. and Robert L. Stokes (1989), "The Canada-United States Pacific Salmon Treaty," Canadian Oceans Policy: National Strategies and the New Law of the Sea, D. McRae and G. R. Munro, eds, (U.B.C. Press), 17-35.

Nash, John F. (1953), "Two-person Cooperative Games," Econometrica 21: 128-140.

Plourde, Charles and David Yeung (1989), "Harvesting of a Transboundary Replenishable Fish Stock: A Non-cooperative Game Solution," Marine Resource Economics 6: 57-70.

Vislie, Jon (1987), "On the Optimal Management of Transboundary Renewable Resources: a Comment on Munro's Paper," Canadian Journal of Economics 20: 870-875. 